\title{
Mucormycosis in a diabetic
}

\author{
V. K. BATRA \\ M.D. \\ M.D. \\ P. S. GUPTA \\ M.D. \\ Department of Medicine, Maulana Azad Medical College and \\ Associated Hospitals, New Delhi-110002, India
}

M. GAIHA

\section{Summary}

A case of juvenile diabetes mellitus with rhino-orbital mucormycosis treated successfully with amphotericin $B$ is described.

\section{Introduction}

Mucormycosis is an acute, often fatal infection caused by saprophytic fungi, of the order Mucorales. It occurs in debilitated patients who are compromised immunologically due to uncontrolled diabetes lymphoma, corticosteroid treatment and radiotherapy (Jain et al., 1978). Only 13 cases were reported up to 1963 (Pilsbury and Fischer, 1977).

The fungus appears in tissues as hyphae which are irregular, non-septate and tend to branch nearly at right angles. It gains access by inhalation, involves palate, pharynx and nasal mucosa by contiguous spread and leads to infarction and gangrene of the sites involved (Abramson, Wilson and Arky, 1967). It may later spread to the paranasal sinuses, cribiform plate, meninges and brain. Mucormycosis of the paranasal sinuses and orbit has been reported to occur rarely without gross cerebral lesions (Baker and Durham, 1957); these cases are the ones that more often recover and the following case belonged to this category.

\section{Case report}

An 18-year-old male was admitted to L.N.J.P.N. (Irwin) Hospital, New Delhi, in April 1980 complaining of abdominal pain for 10 days and recent vomiting. He was found to be malnourished, dehydrated and acidotic, with mild ptosis of his left eye. Urine examination revealed massive glycosuria and ketonuria. The treatment of diabetic ketoacidosis was immediately started. During the next $48 \mathrm{hr}$ he developed complete ptosis, total internal and external ophthalmoplegia with loss of corneal sensation in the left eye. Fundus examination revealed a picture resembling orbital cellulitis. Vision was grossly impaired. A sero-sanguinous discharge was noticed from his left nostril and turbinates were found to be covered with a black necrotic membrane. During the next $24 \mathrm{hr}$ the nasal lesions progressed leading to perforation of the nasal septum and depression of the bridge of the nose (Fig. 1). Simultaneously, a blackish brown necrotic patch was noticed on the left side of the hard palate which lead to palatal perforation (Fig. 2). A diagnosis of mucormycosis was made and the patient was put on intravenous amphotericin B which was initially started in a dose of $0.25 \mathrm{mg} / \mathrm{kg}$ body weight, later increased to 1 $\mathrm{mg} / \mathrm{kg}$ body weight and a total of $2.0 \mathrm{~g}$ of drug was given. In the next few days, nasal secretions as well as the eye lesion dried up and the patient gradually improved and was discharged. At the time of the provisional diagnosis of mucormycosis, palatal biopsy produced very little bleeding and microscopic examination revealed irregular non-septate fungal hyphae (characteristic of Mucorales) with necrotic tissue and a polymorphnuclear reaction. X-rays of chest, orbit, skull and optic formina were normal. Xrays of the paransal sinuses revealed bilateral maxillary sinusitis. The white cell count and renal function tests were normal.

\section{Discussion}

Mucormycosis is generally an acute infection of paranasal sinuses with cerebral involvement and a fatal outcome but it can present with pulmonary or gastrointestinal infection. It was first described in humans by Paltauf (Pilsbury and Fischer, 1977). Furbinger in 1876 described two cases of pulmonary mucormycosis but it was as late as 1943 that Gregory reported mucor originating in paranasal sinuses (Beeson, McDermott and Wyngaarden, 1979). The 


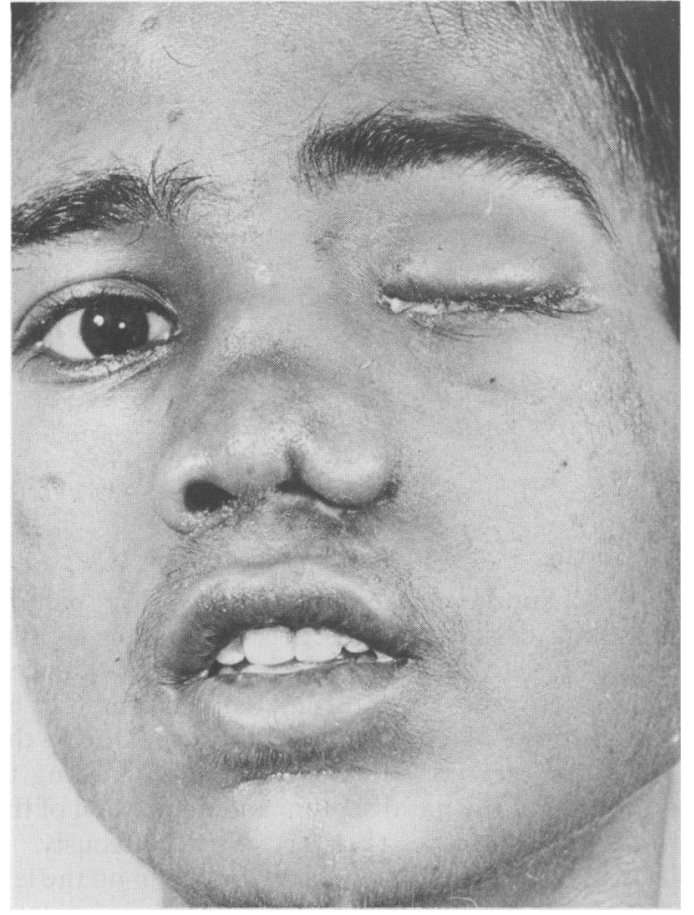

FIG. 1. Showing involved left eye with ptosis and depressed nasal bridge.

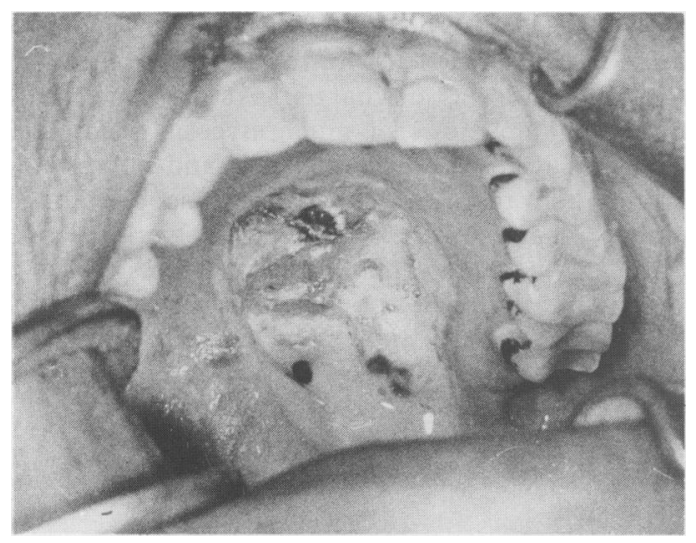

FIG. 2. Hard palate showing perforation.

rhinocerebral form accounts for 50\% of all cases of mucormycosis (Pilsbury and Fischer, 1977); cases such as the present one without cerebral involvement occur rarely (Baker and Durham, 1957).

Mucormycosis of the paranasal sinuses and contig- uous structures occurs especially in poorly controlled diabetics with ketosis (Abramson et al., 1967). Diabetes is associated with $50 \%$ of all cases of mucormycosis but is present in $75-80 \%$ of cases of rhinoorbital mucormycosis (Pilsbury and Fischer, 1977; Castelli and Pallin, 1978). This latter condition resembles septic cavernous sinus thrombosis but which is, however, characterized by marked exophthalmos early in the disease (Walsh and Hoyt, 1969) with minimal visual loss. The former feature was absent whereas vision was grossly impaired in our case. The presence of characteristic nasal and palatal lesions, the absence of toxaemia and minimal bleeding on cutting the palatal lesion were also of value in making the diagnosis.

Internal and external ophthalmoplegia with loss of corneal sensation in this case is explained by an exudative reaction at the apex of the orbit (Pilsbury and Fischer, 1977; Castelli and Pallin, 1978). Although this finding may be due to invasion of the cavernous sinus by the fungus (Castelli and Pallin, 1978) the absence of proptosis or any other sign of central nervous system involvement made such spread unlikely in this case.

Headache, mild fever, lethargy, facial swelling and intranasal necrosis is found in all cases of rhinocerebral mucormycosis (Pilsbury and Fischer, 1977). Gross reduction in vision, external ophthalmoplegia, nasal discharge and internal ophthalmoplegia were reported in $92 \%, 69 \%, 69 \%$ and $54 \%$ of cases (Abramson et al., 1967). Focal bone destruction with mucosal thickening of sinuses is reported in $60 \%$ of cases although absent in ours. The disease has a progressive and fatal course if untreated and only seven patients are reported to have survived before the introduction of amphotericin $B$.

\section{References}

AbRAmSON, E., WILSON, D. \& ARKY, R.A. (1967) Rhinocerebral phycomycosis in association with diabetic ketoacidosis. Annals of Internal Medicine, 66, 735.

BAKER, R.D. \& DURhAM, N.C. (1957) Mucormycosis-a new disease. Journal of the American Medical Association, 163, 805.

BeEson, P.B., MCDERMOTT, W. \& WyngaARDEN, J.B. (1979) Cecil and Loeb Text Book of Medicine, 15th Asian Ed. p. 545. W.B. Saunders, Japan.

CASTelli, J.B. \& PAllin, J.L. (1978) Lethal rhinocerebral phycomycosis in a healthy adult - a case report and review of literature. Otolaryngology, 86, 696.

JaIN, J.K., Markowitz, A., KhIlanani, P.V. \& LaUter, C.B. (1978) Localized mucormycosis following intramuscular corticosteroid: case report and review of literature. American Journal of the Medical Sciences, 275, 209.

PILSBURY, H.C. \& FiSCHER, N.D. (1977) Rhinocerebrai mucormycosis. Archives of Otolarnygology, 103, 600.

WALSH, F.B. \& HOYT, W.F. (1969) Clinical Neuro-opthalmology. 3rd Ed. p. 1487. William and Wilkins, Baltimore. 